\title{
Aggravation of Aluminum Phosphide Induced Liver Damage and Hematotoxicity in Adult Wistar Rat: The Role of Allium Sativum
}

\author{
E. U. Eric, V. E. Boloya, and A. E. Osuamkpe
}

\section{ABSTRACT}

Objectives: To investigate the ameliorative effect of garlic extract on Aluminum Phosphide induced toxicity on the liver and kidney of adult Wistar rats.

Materials: Thirty six (36) male adult Wistar rats weighing $180 \pm 20-250 \pm 30 \mathrm{~g}$ were purchased from Dantom Farms, Swali, Bayelsa State and moved to the animal house of the department of Medical Laboratory Science, Niger Delta University. The animals were assigned into six (6) major groups with six (6) animals in each group after the period of acclimatization: Animals in Group A (Control): received pelleted growers mash (feed) and water. Group B (Positive Control received $0.014 \mathrm{mg}$ of Aluminum Phosphide only. Group C: received $0.014 \mathrm{mg}$ of Aluminum Phosphide and $250 \mathrm{~g}$ of garlic extract. Group D: received $0.014 \mathrm{mg}$ of Aluminum Phosphide and $500 \mathrm{mg}$ of garlic extract. Group E: received $500 \mathrm{mg}$ of garlic extract, Group F: received $0.6 \mathrm{ml}$ of oil at the end of the treatment, the liver and the kidney of each sacrificed rat were processed for paraffin sectioning and stained with Harris hematoxylin and eosin.

Result: Photomicrograph of the liver of animals in Groups B, C and D show central venous congestion, degeneration, hemorrhage, sinusoidal dilation, bile stasis, centrilobular necrosis, Kupffer cell hyperplasia, inflammatory cells and fat infiltration which are features of hepatic injury also photomicrograph of the kidney of animals in Groups B, C and D shows membranous defect, contracted glomeruli with marked presence of mesangial cells, areas of tubular necrosis with mesangial cells proliferation. while the other groups (Group A, E, F) did not show any histological change in comparison with control.

Conclusion: The present study proves that the oral ingestion of Aluminum Phosphide induces hepatotoxicity and inflammation of the liver and kidney. It also shows that the use of garlic at various concentrations $(250 \mathrm{mg} / \mathrm{l}$ and $500 \mathrm{mg} / \mathrm{l}$ ) aggravates the tissue damage even more, and also garlic extract does not have ameliorative effect on aluminum phosphide toxicity on the liver and kidney of albino wistar rats.

Keywords: liver, kidney, garlic, aluminum phosphide, toxicity, wistar rats.
Published Online: March 31, 2021

ISSN: 2684-5199

DOI:10.24018/ejbio.2021.2.2.176

\section{E. U. Eric *}

Department of Medical Laboratory Sciences, Faculty of Basic Medical Sciences, Niger Delta University, Wiberforce Island, Bayelsa state, Nigeria.

(e-mail: drericuchenna@gmail.com)

V. E. Boloya

Department of Chemical Pathology, Faculty of Basic Medical Sciences, Niger Delta University, Wiberforce Island, Bayelsa state, Nigeria.

A. E. Osuamkpe

Department of Medical Laboratory Sciences, Faculty of Basic Medical Sciences, Niger Delta University, Wiberforce Island, Bayelsa state, Nigeria.

*Corresponding Author

\section{INTRODUCTION}

Over the years, it has become common practice for farmers to use fumigants, pesticides, herbicides, insecticides and similarly disturbing alternatives to counter pests and the destruction they bring. The use of synthetic insecticides has been the major means through which cowpea seeds are protected during storage. The use of synthetic pesticides with time has revealed the nuisance they constitute to the ecosystem such as their undesirable side-effects on non-target organisms including man and the fact that they are environmentally disruptive [1]. In 2015, the European Union (EU) banned Nigerian beans because of the high level of dichlorvos (2, 2-dichlorovinyl dimethyl phosphate - DDVP) pesticide residue in already processed beans. DDVP, popularly known in Nigeria as "Sniper" is a potent fumigant easily obtainable at affordable prices. On September $23^{\text {rd }}$ 1996 in Lagos, Nigeria, 14 people died after eating beans previously preserved with DDVP; an incidence popularly known as "killer beans" Resorting to the use of aluminum phosphide tablets which is seen as a dry white powder in raw beans was an option so effective countless crop producers indulged in.

Aluminum phosphide is a highly toxic inorganic compound used as wide band gap semi-conductor. It is a cheap, grey, solid fumigant and a highly toxic pesticide which is (commonly but wrongly) used for grain preservation. It has been in use since the 1950's and is known by different names in various countries. In India, it is marketed as a tablet of celphos, alphosquick phos and phostoxin. In Iran, it is known 
as the rice tablet [2] that can be purchased in local shops. In Nigeria, it is sold as Phostoxin, Cejphos, Justoxin, Force Toxin, Multiphos etc. This highly toxic chemical is cheap and usually formulated in tablets or pellets, granules and as powder. Upon contact with moisture, aluminum phosphide liberates phosphine which is the active pesticidal component [3]. Human toxicity, which is usually acute, occurs due to the toxic effects of phosphine released in the stomach after ingestion of aluminum phosphide. Phosphine is widely absorbed from the gastrointestinal tract. It emerges as a poison of suicidal deaths as this pesticide is cheap, freely available and is a "sure agent of death" [4]. In Iran, Aluminum Phosphide is known as rice tablet [2], is easily accessible in spite of restriction laws especially in India where it is the most commonly used pesticide and suicide drug. [5]. Overall mortality is 70-100\%. Mortality is highest in victims who ingest three tablets (all of whom die), higher in victims who consume two tablets and less in those who consume one. Suicide is the most common cause use (94\%), followed by accidental use (5\%) and homicide (1\%) [6]. In human liver within the nucleus, aluminum phosphide initiates lipid peroxidation and DNA oxidation, sinusoidal congestion [7].

Garlic is a plant in the onion (Allium) family made up of segments called cloves that make up a bulb. Although commonly used in flavoring food, garlic is largely employed for its medicinal benefits which are attributed to the sulfur compounds produced when garlic is chopped. Allicin [8] is the most important of these sulfur compounds but because of its volatile nature, it is easily lost shortly after garlic has been crushed or chopped. Other sulfur compounds include diallyl disulfide and s-allyl cysteine. The sulfur compounds are absorbed in the digestive tract by cells and distributed throughout the body. Considering the key compound Allicin, garlic is said to be hepatoprotective because it can reduce oxidative damage [9]. SAC (S-allycysteine) is a stable, odorless, water-soluble compound with the ability to antioxidize [10] and protect the liver from toxins [11]. Studies have shown that even as low a quantity as $10 \mu \mathrm{M}$ of allicin can significantly increase the glutathione reductase activity. Allicin can also reduce free radical scavenging to lower lipid peroxidation [12]. This means that allicin potentially improves the antioxidation and detoxification capabilities of hepatocytes.

Previous studies have shown that exposure to chemicals like pesticides can alter hematological parameters in animals [13] and humans [14]. Also, in previous studies, the main hematological alterations induced by aluminum phosphide exposure include anemia, thrombocytopenia, and leukopenia. Our study associated aluminum phosphide exposure with significant decreases in RBC, HCT, and RDW values, while $\mathrm{MCV}, \mathrm{MCH}$, and $\mathrm{MCHC}$ values were significantly increased. The reduction in both RBC and HCT values is indicative of an aluminum phosphide -induced anemia in the rats, which is in agreement with earlier reports on the hemato toxic effect of pesticides, including aluminum phosphide [15].

After aluminum phosphide ingestion, phosphine concentration is reported to increase in the blood and liver [16]. Studies have also shown that the absorbed aluminum phosphide, as well as, its gaseous product phosphine can react with free hemoglobin and hemoglobin in normal red blood cells to produce hemichrome, a derivative of methemoglobin and Heinz bodies [17] with the concomitant induction of free radicals [18]. Oxidation of lipids and proteins by these free radicals can cause an increase in the production of lipid peroxides leading to hemolysis of RBC [19]. The major pathological consequences of free radical-induced membrane lipid peroxidation include increased membrane rigidity, decreased cellular deformability, reduced erythrocyte survival, and lipid fluidity, all of which will eventually result in the lysis of the erythrocyte [20]. The decreased RBC observed in previous study may, therefore, result from increased erythrocyte destruction predicated by oxidative stress. besides, pesticide residues are known to induce anemia by interfering in several steps in heme biosynthesis, causing a shortening of circulating erythrocytes life span.

The aim of this research is to investigate the effect of garlic extract on Aluminum Phosphide induced toxicity on the liver, kidney, and hematological parameters (FBC) of adult Wistar rats.

\section{MATERIALS AND METHOD}

\section{A. Location of Study}

This study was carried out in the Department of Medical Laboratory Science, Faculty of Basic Medical Sciences, College of Health Sciences, Niger Delta University, Wilberforce Island Amassoma, Bayelsa State of Nigeria.

\section{B. Substance of Study}

\section{Aluminum Phosphide}

The aluminum phosphide produced by Excell Crop Care Limited. Registered Office: 184-87, S.V. Road, Jogeshwari (west), Mumbai -400102, Maharaahtra, India. It was purchased in a local agro-chemicals retail shop in Amassoma in the formulation of twenty $3 \mathrm{~g}$ tablets in a sealed tube and administered through a locally made galvaging tube (orally) for seven days

\section{Garlic Extraction}

Raw garlic was purchased in the local market and extract was prepared. $500 \mathrm{~g}$ of Allium sativum bulbs were crushed and added to $100 \mathrm{ml}$ of distilled water. The juice was extracted using an electric blender. The mixture was filtered and centrifuged using a macro-centrifuge at 12,000 RPM for 10 minutes. The supernatant was transferred to a clean bottle and stored at $4{ }^{\circ} \mathrm{C}$. The concentration was considered $500 \mathrm{mg}$ based on the weight of the paste/ml [21].

\section{Vehicle}

Olive oil was used as an inert medium to dissolve and transport the substance of interest (Aluminum phosphide) to boycott the in vitro production of phosphine gas according to Olusegun Kayode et al. [22].

\section{Experimental Animals}

Thirty six (36) adult male Wistar rats weighing 180 \pm 20 $250 \pm 30 \mathrm{~g}$ were purchased from Dantom Farms, Swali, Bayelsa State and moved to the animal house of the department of Medical Laboratory Science, Niger Delta University, Amassoma where they were housed under standard temperature of $\left(27 \pm 5^{\circ} \mathrm{C}\right)$ with twelve hours light and dark cycles in both aluminum and mesh barricaded plastic 
cages. The rats were allowed to acclimatize for 18 days ad libitum during this period with water and Super Starter feed.

E. Experimental Layout

TABLE I: EXPERIMENTAL LAYOUT

\begin{tabular}{|c|c|c|c|c|c|c|}
\hline Groups & $\begin{array}{c}\text { A } \\
\text { (control) }\end{array}$ & $\begin{array}{c}\text { B } \\
\text { (AlP) }\end{array}$ & $\begin{array}{c}\mathrm{C} \\
\text { (AlP } \\
\text { and } 500 \\
\mathrm{mg} / \mathrm{ml} \\
\text { Garlic) }\end{array}$ & $\begin{array}{c}\mathrm{D} \\
\text { (AlP and } \\
500 \\
\mathrm{mg} / \mathrm{ml} \\
\text { garlic) }\end{array}$ & $\begin{array}{c}\mathrm{E} \\
\text { (Garlic } \\
\text { only) }\end{array}$ & $\begin{array}{c}\text { F } \\
\text { (Oil) }\end{array}$ \\
\hline $\begin{array}{l}\text { Number of } \\
\text { animals }\end{array}$ & 6 & 6 & 6 & 6 & 6 & 6 \\
\hline
\end{tabular}

\section{F. Substance Administration}

All the animals were fed with Super Starter and water.

Group A (control): Six rats for control received water and feed only.

Group B: Six rats received $0.014 \mathrm{mg}$ of Aluminum Phosphide only.

Group C: Six rats received $0.014 \mathrm{mg}$ of Aluminum

Phosphide and $250 \mathrm{~g}$ of garlic extract.

Group D: Six rats received $0.014 \mathrm{mg}$ of Aluminum Phosphide and $500 \mathrm{mg}$ of garlic extract.

Group E: Six rats received $500 \mathrm{mg}$ of garlic extract.

Group F: Six rats received $0.6 \mathrm{ml}$ of oil.

\section{G. Sample Collection}

At the end of seven days of administration, the rats were sacrificed by administering diethyl ether as anesthesia. The rats were then dissected to harvest their livers and kidney which were immediately rinsed in normal saline and fixed in $10 \%$ formalin also 2.0 milliliters of blood were collected into K3 EDTA anticoagulant bottles and were analyzed automatically for packed cell volume (PCV), Haemoglobin (Hb), estimating Red cell count total white cell count (WBC), platelet count, mean corpuscular volume (MCV), mean corpuscular haemoglobin concentration (MCHC) using an autoanalyzer.

\section{H. Blood Sample Analysis}

The methodology is by flow cytometry (direct current method) using suitable cell packs according to manufacturer's specification for the desired cell population using SYSMEX KX-IN auto-analyzer machine instrument
[23].

The SYSMEX KX-IN is a three part differential haematological analyzer that process approximately sixty (60) samples per hour and shows on the LCD (Liquid Crystal Display) screen. The particle distribution curves of white blood cell, red blood cell and platelets along data of 19 other parameters were produced as the analysis result.

\section{Tissue Processing}

The tissues were processed using automatic tissue processor (LEICA TP 1020) according to standard histological processing schedule. Using a rotary microtome (Heitz 150, Cambridge model) and stained with hematoxylin and eosin ( $\mathrm{H}$ and $\mathrm{E})$ staining technique at the histopathology laboratory department of the Niger Delta University Teaching Hospital (NDUTH), Okolobri.

\section{J. Microscopy and Photomicrography}

Microscopy was done using an Olympus binocular light microscope at magnification $\mathrm{x} 400$ and the sections were photographed using a digital camera.

\section{K. Statistical Analysis}

Raw data generated from the research work were computed and analyzed using statistical software (SPSS version 25). Graphical representations and descriptive statistics of mean, standard deviation was calculated. Data was displayed in scatter plot matrix.t-test and one way ANOVA were used. Pair-wise correlation was also performed to determine the association between the variables.

\section{RESULTS}

The results of the analysis are expressed as mean \pm standard deviation. The results are expressed in different tables. The red cell indices among the various groups $(\mathrm{B}, \mathrm{C}, \mathrm{D}, \mathrm{E}$ and $\mathrm{F})$ as compared to the control group (A) are as shown in Table II. Table III shows the mean and standard deviation of white blood cell parameters among the various groups as compared to the control. Table IV shows the variance between the groups and the control with the $\mathrm{p}$-values and t-values indicated. $\mathrm{P}$ values of $\leq 0.05$ at $95 \%$ confidence interval are considered significant.

TABLE II: RESULTS OF RED BLOOD CELL INDICES OF THE DIFFERENT GROUPS AND CONTROLS

\begin{tabular}{ccccccc}
\hline Parameters & Control & Group B & Group C & Group D & Group E & GROUP F \\
\hline PCV & $43.33 \pm 4.45$ & $40.42 \pm 3.31$ & $36.00 \pm 6.98$ & $38.14 \pm 5.01$ & $33.83 \pm 3.87$ & $40.86 \pm 6.47$ \\
Hb & $12.90 \pm 2.18$ & $12.62 \pm 0.89$ & $11.13 \pm 1.38$ & $11.70 \pm 1.03$ & $11.38 \pm 1.12$ & $12.71 \pm 1.38$ \\
PLT & $178.00 \pm 25.14$ & $230.86 \pm 27.41$ & $176.50 \pm 9.88$ & $249.86 \pm 42.67$ & $235.17 \pm 50.83$ & $252.86 \pm 59.89$ \\
MCV & $73.33 \pm 12.01$ & $80.29 \pm 7.15$ & $78.30 \pm 8.09$ & $68.96 \pm 31.35$ & $79.42 \pm 9.93$ & $71.69 \pm 16.03$ \\
MCH & $23.70 \pm 4.35$ & $24.97 \pm 2.85$ & $22.05 \pm 3.43$ & $23.94 \pm 5.89$ & $25.72 \pm 5.53$ & $24.69 \pm 5.15$ \\
MCHC & $29.80 \pm 3.21$ & $31.60 \pm 2.90$ & $28.03 \pm 2.99$ & $30.29 \pm 2.48$ & $27.33 \pm 3.01$ & $29.40 \pm 3.39$ \\
MXD & $12.33 \pm 4.65$ & $12.71 \pm 5.74$ & $9.50 \pm 4.51$ & $11.57 \pm 5.00$ & $9.83 \pm 3.82$ & $6.71 \pm 3.55$
\end{tabular}

PCV - Packed cell volume; Hb - Haemoglobin; PLT - Platelet; MCV - Mean Cell Volume; MCH - Mean Cell Haemoglobin; MCHC - Mean Cell Haemoglobin Concentration; MXD - Mixed Cell Percentage.

TABLE III: INDICATES THE RESUlTS OF THE WHITE BLOOD CELL PARAMETERS OF THE GROUPS AND CONTROLS

\begin{tabular}{ccccccc}
\hline Parameters & Control & Group B & Group C & Group D & Group E & Group F \\
\hline WBC & $7.50 \pm 4.42$ & $9.00 \pm 7.11$ & $15.75 \pm 1.11$ & $10.23 \pm 3.64$ & $10.35 \pm 4.20$ & $13.07 \pm 7.12$ \\
NEUT & $40.33 \pm 20.35$ & $48.57 \pm 18.62$ & $35.50 \pm 14.84$ & $66.86 \pm 10.93$ & $65.83 \pm 10.46$ & $48.86 \pm 18.93$ \\
LYMPH & $47.33 \pm 23.62$ & $37.43 \pm 18.40$ & $52.25 \pm 21.39$ & $22.57 \pm 9.80$ & $24.17 \pm 8.23$ & $42.43 \pm 21.01$ \\
\hline
\end{tabular}

WBC - White Blood Cell count; NEUT - Neutrophil; LYMPH - Lymphocyt. 
European Journal of Biology and Biotechnology www.ejbio.org

TABLE IV: COMPARISON BETWEEN THE DIFFERENT TEST GROUPS AND THE CONTROL

\begin{tabular}{|c|c|c|c|c|c|c|}
\hline Parameters & Control & Group B & Group C & Group D & Group E & Group F \\
\hline PCV & 0.01 & $0.216(37.37-43.49)$ & $0.149(24.90-41.10)$ & $0.135(33.51-42.478)$ & $0.007(29.77-37.89)$ & $0.549(34.88-46.84)$ \\
\hline $\mathrm{Hb}$ & 0.01 & $0.687(11.81-13.45)$ & $0.127(8.91-13.33)$ & $0.135(10.74-12.66)$ & $0.094(10.21-12.55)$ & 0.842 (11.44-13.99) \\
\hline PLT & 0.01 & $0.017(205.51-256.20)$ & $0.897(160.77-192.23)$ & $0.025(210.40-289.32)$ & $0.109(181.83-288.51)$ & $0.073(197.51-308.20)$ \\
\hline $\mathrm{MCV}$ & 0.01 & $0.191(73.67-86.90)$ & $0.4301(65.42-91.18)$ & $0.745(49.21-88.85)$ & $0.378(68.99-88.85)$ & $0.871(56.86-86.51)$ \\
\hline $\mathrm{MCH}$ & 0.01 & $0.662(22.34-27.61)$ & $0.676(13.99-17.51)$ & $0.955(6.87-13.59)$ & $0.638(5.94-14.76)$ & $0.802(6.48-19.66)$ \\
\hline $\mathrm{MCHC}$ & 0.01 & $0.464(28.92-34.28)$ & $0.557(23.27-32.78)$ & $0.828(27.99-32.58)$ & $0.355(24.17-30.49)$ & $0.880(26.26-32.54)$ \\
\hline MXD & 0.01 & $0.935(7.41-18.02)$ & $0.588(2.32-16.68)$ & $0.860(6.95-16.19)$ & $0.546(5.83-13.84)$ & $0.159(3.44-9.93)$ \\
\hline WBC & 0.01 & $0.749(2.43-15.53)$ & $0.008(13.99-17.51)$ & $0.311(6.87-13.59)$ & $0.355(4.94-14.76)$ & $0.245(6.48-19.66)$ \\
\hline NEUT & 0.01 & $0.554(31,35-65.79)$ & $0.736(11.88-59.11)$ & $0.027(56.75-76.97)$ & $0.041(54.86-76.81)$ & $0.545(31.35-66.37)$ \\
\hline LYMPH & 0.01 & $0.441(20.41-54.45)$ & $0.752(81.21-86.29)$ & $0.014(13.51-31.63)$ & $0.019(15.53-32.81)$ & $0.729(22.99-61.86)$ \\
\hline
\end{tabular}

P-values are considered significant at $\leq 0.05$ at $95 \%$ confidence interval. Significant values are expressed in bold fonts.

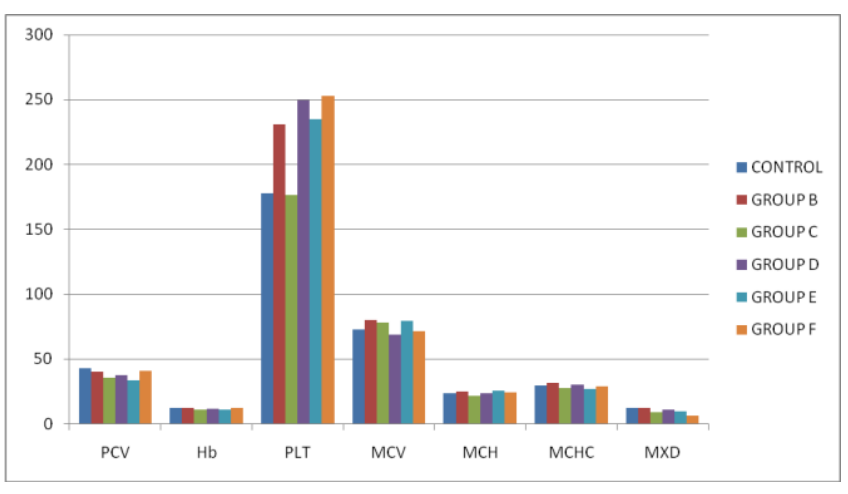

Fig. 1. Mean values of the red cell indices of the different test and control groups.

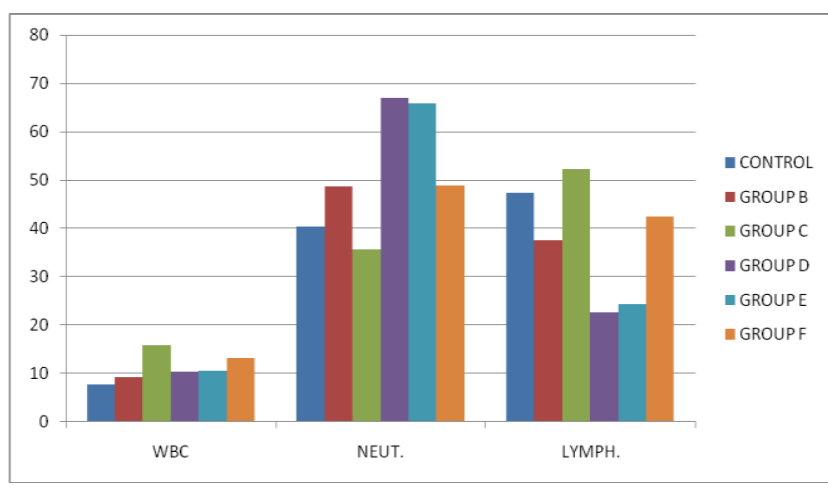

Fig. 2. Mean values of the white blood cell parameters of the various test and control groups.

\section{A. Histology Photomicrograph Plate}

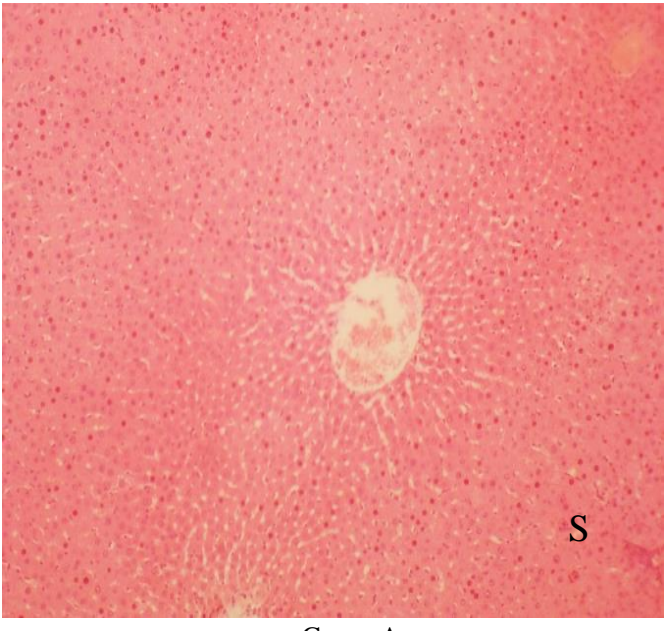

Group A

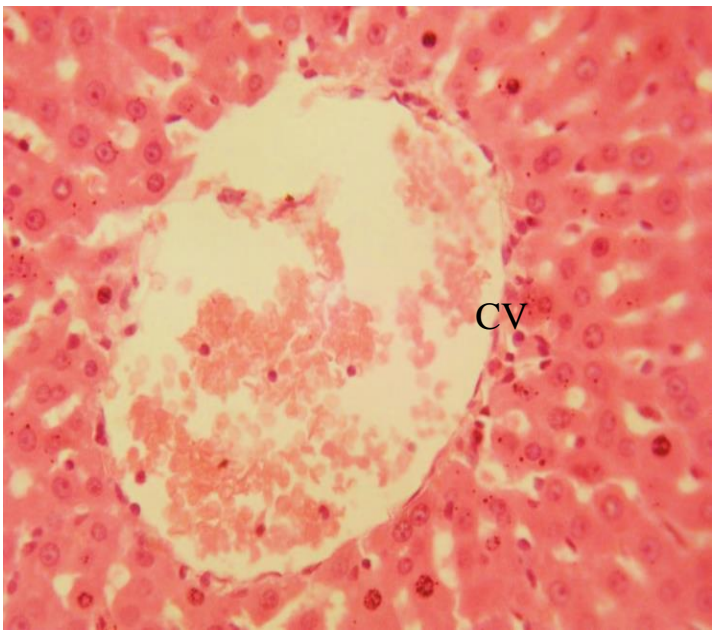

Group B

Plate 1. Shows the morphology of the liver after the administration of the various treatments for 7 days. Slide shows normal morphology of the liver, centralvein (CV), hepatocytes with intact sinusoidal space (S) (X10, X40).

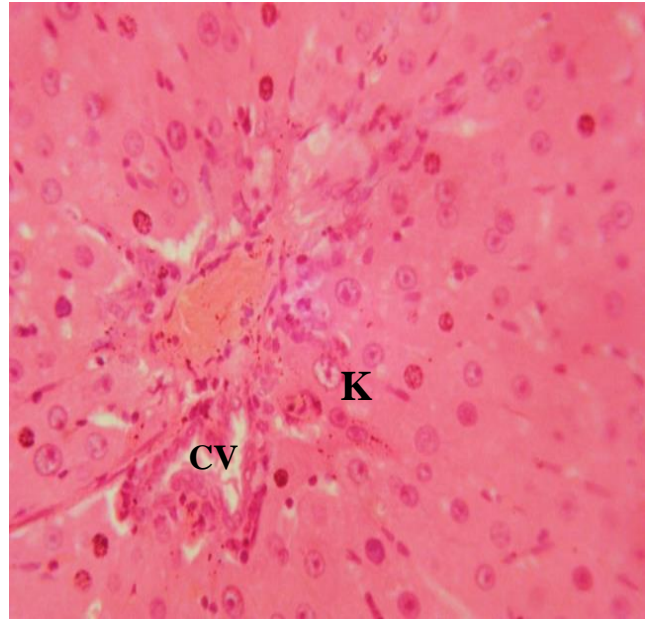

Group B

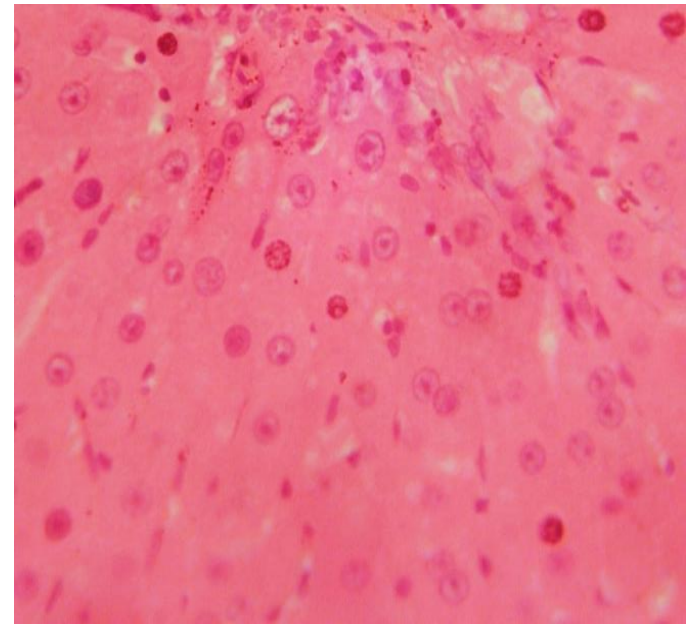

Group B

Plate 2. Shows the morphology of the liver after the administration of the various treatments for 7 days. Slide shows congestion of the central vein (CV), areas of necrosis with marked presence of Kupffer cells (K) (X10, X40). 


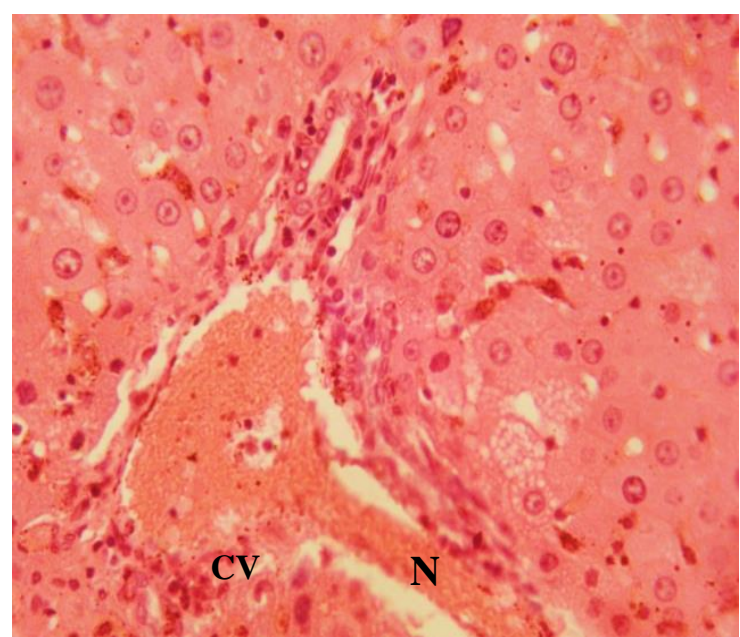

Group C

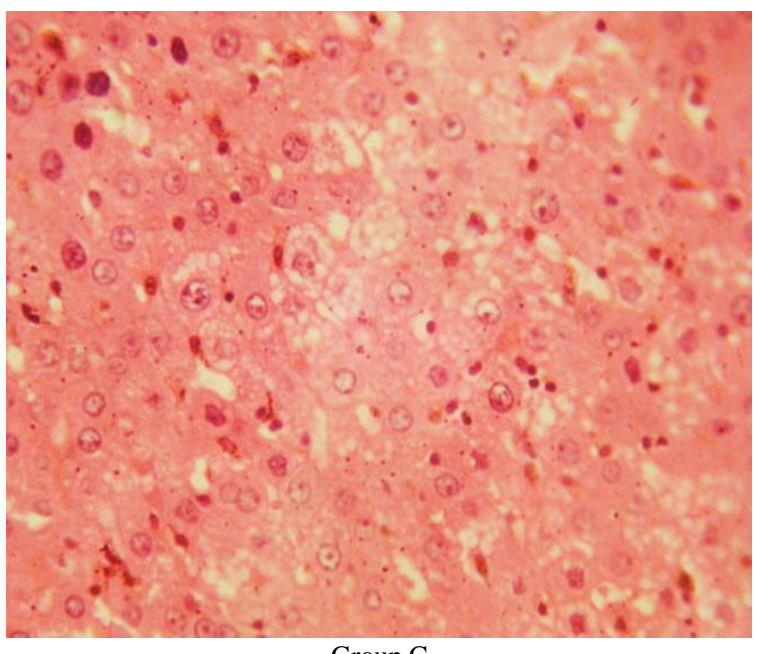

Group C

Plate 3. Shows the morphology of the liver after the administration of the various treatments for 7 days. Slide shows central vein congestion (CV) with areas of lobular necrosis(N), fatty infiltration $(\mathrm{F})$ and marked presence of Kupffer cells (K) (X10, X40).

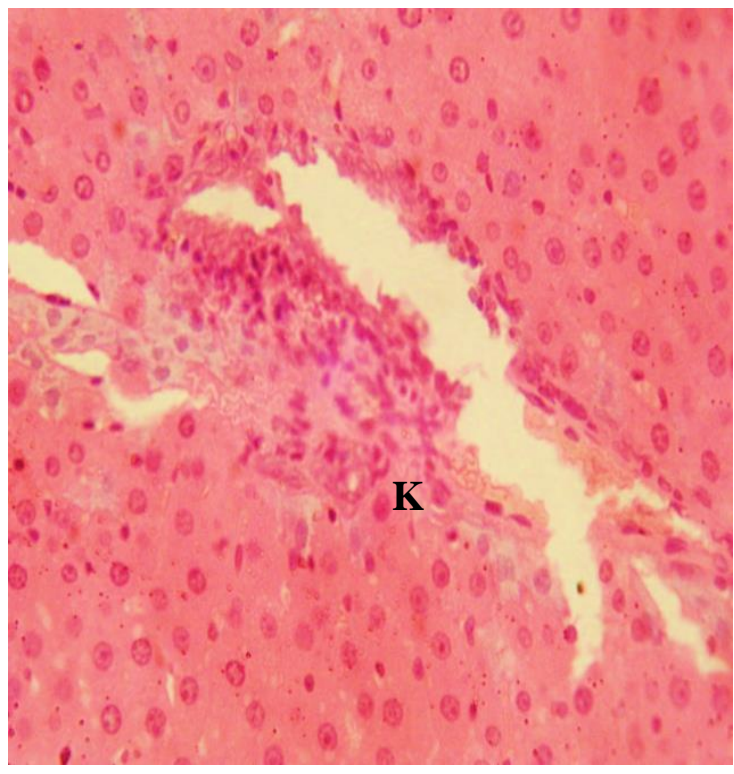

Group D

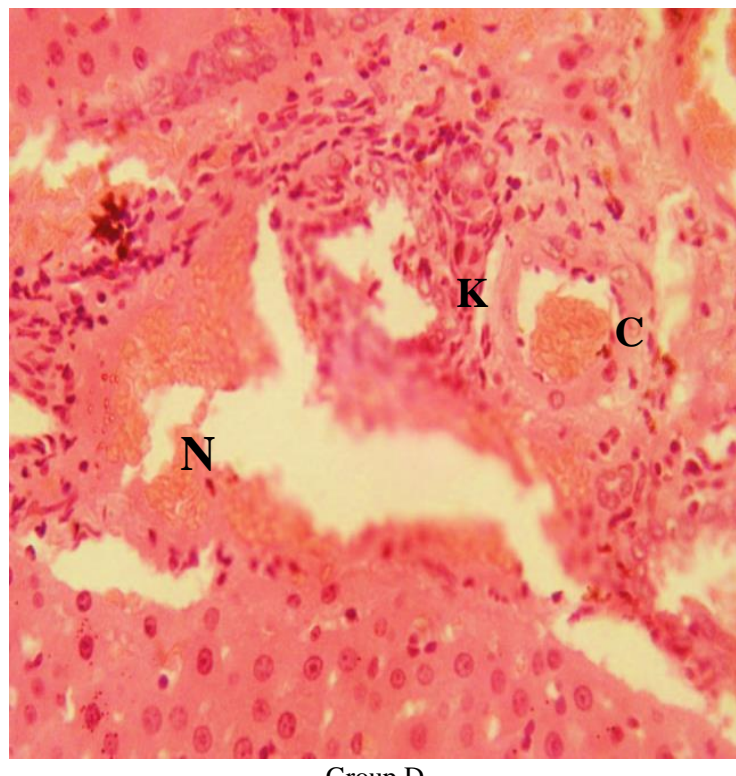

Group D

Plate 4. Shows the morphology of the liver after the administration of the various treatments for 7 days. Slide shows central vein congestion (C) with areas of necrosis $(\mathrm{N})$, large presence of Kupffer cells $(\mathrm{K})(\mathrm{X} 10, \mathrm{X} 40)$.

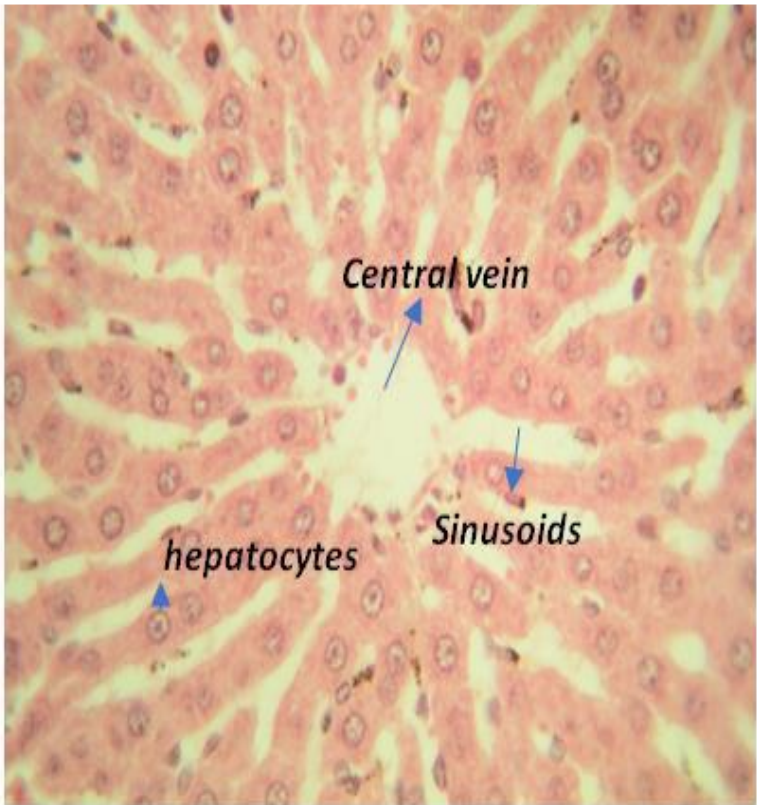

Group E

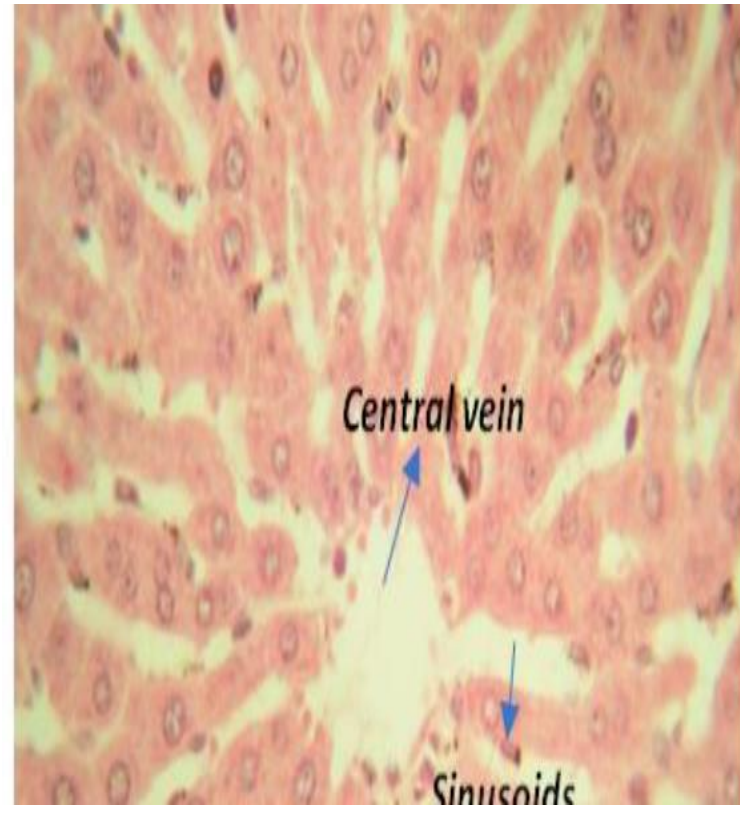

Group E

Plate 5. Shows the morphology of the liver after the administration of the various treatments for 7 days. Slide shows normal morphology of the liver, central vein $(\mathrm{CV})$, hepatocytes with intact sinusoidal spaces (S) (X40). 


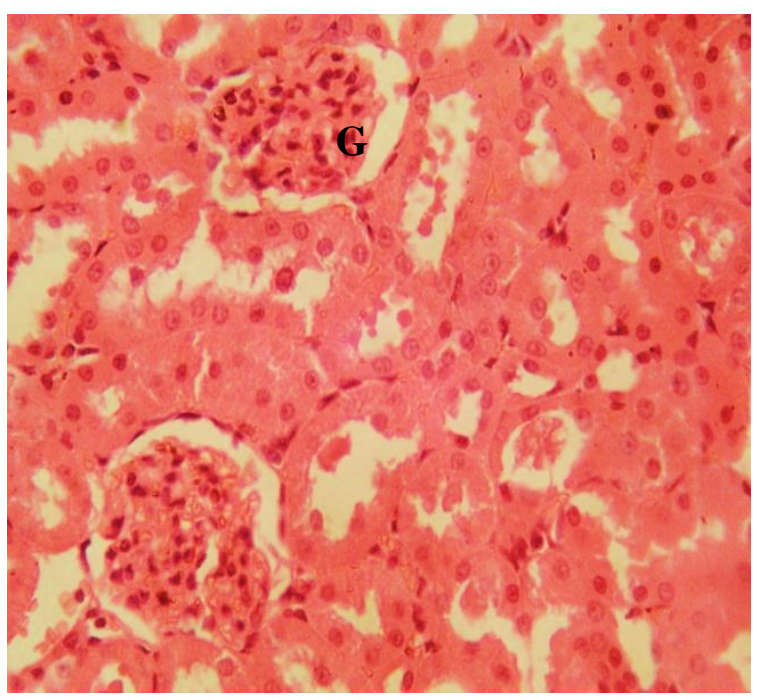

Group A

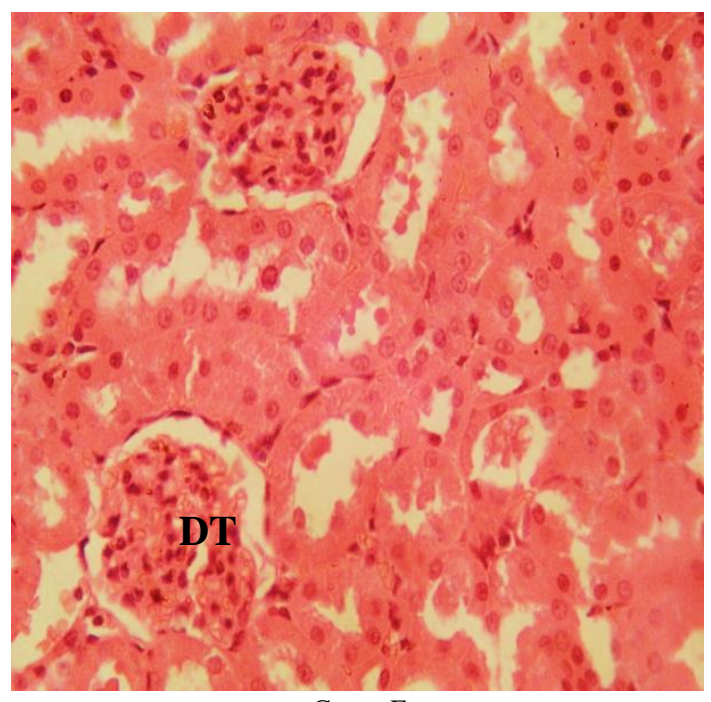

Group F

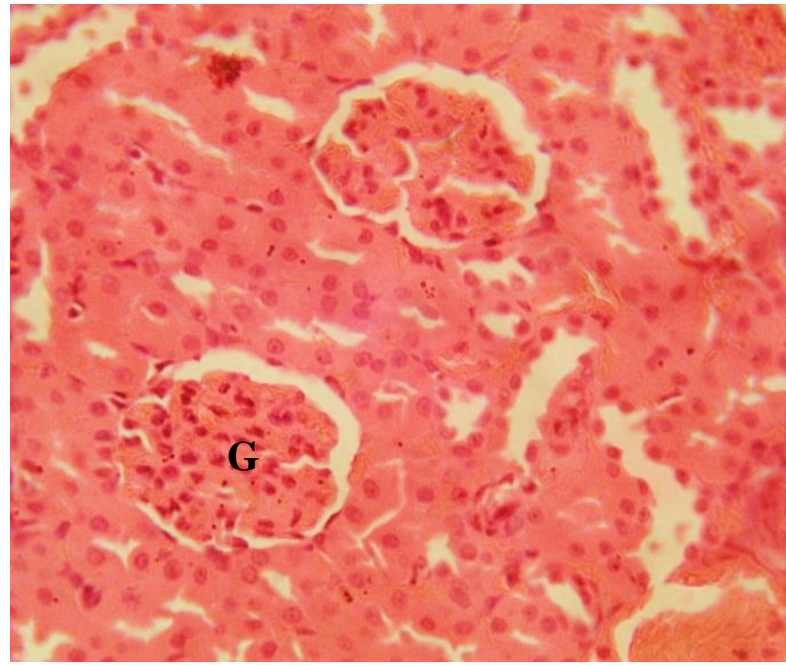

Group E

Plate 6. Shows the Morphology of the kidney after the administration of the various treatments for 7 days. Slide shows normal morphology of the kidney, glomeruli (G), distal tubules (DT) (X40).

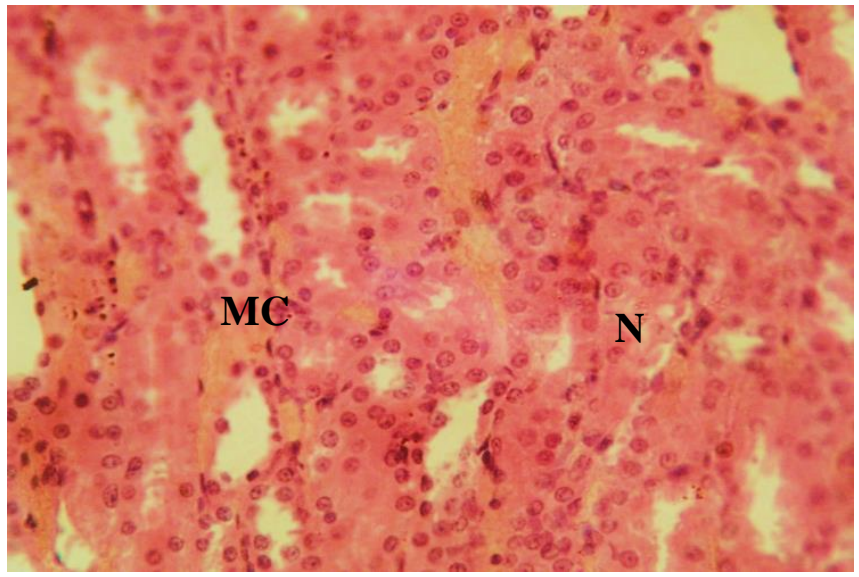

Group B

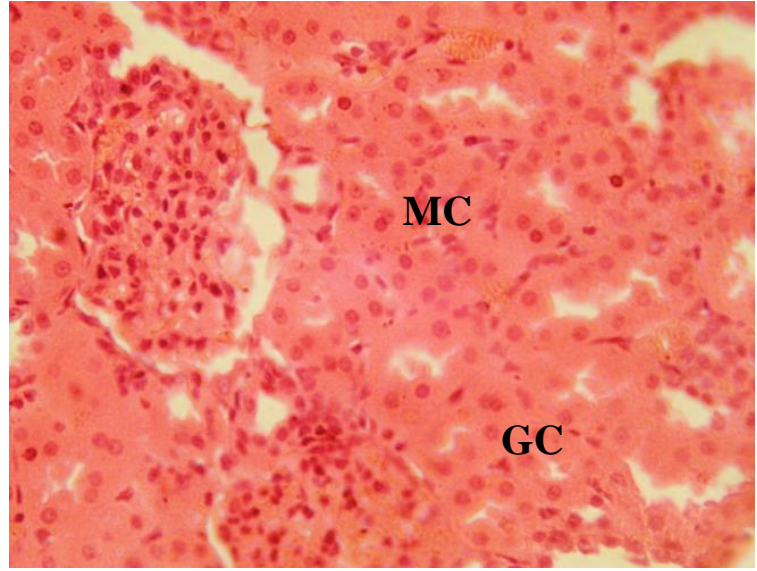

Group B

Plate 7. Shows the Morphology of the kidney after the administration of the various treatments for 7 days. Slide shows areas of tubular necrosis(N), contracted glomeruli (GC)with marked presence of mesangial cells (MC) (X40). 

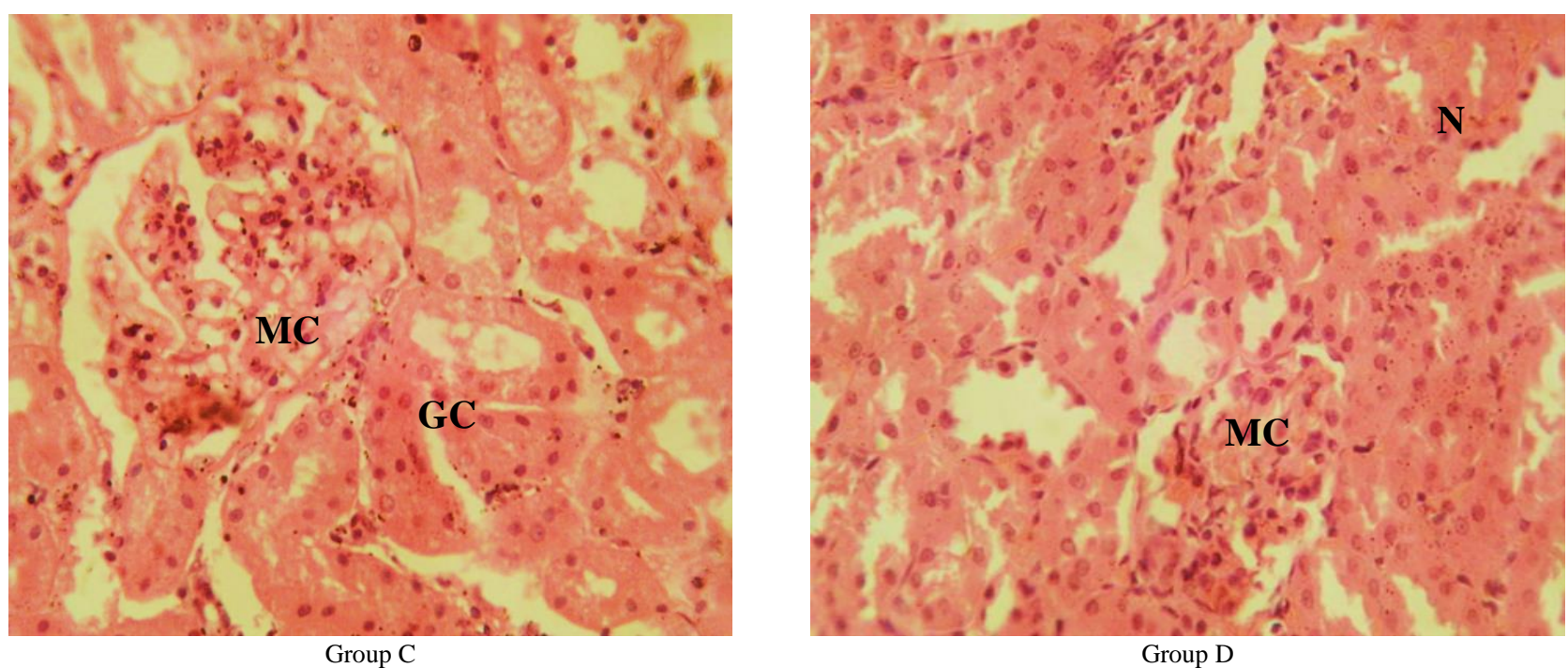

Plate 8. Shows the Morphology of the kidney after the administration of the various treatments for 7 days. Slide shows membranous defect (M), contracted glomeruli (GC)with marked presence of mesangial cells (MC) (X40).

\section{DISCUSSION}

The experimental animals were grouped into six (6) groups and subjected to different treatments. The results of the study as indicated above shows a general increase in red cell indices parameters in group B as compared to the control group, However, this increase is only significant in platelet count $(\mathrm{P}<0.05)$. Other red blood cell indices such as PCV and hemoglobin count showed a non-significant $(\mathrm{P}>0.05)$ decreased from $43.33 \pm 4.45$ to 40.423 .31 and $12.90 \pm 2.18$ to $12.62 \pm 0.89$ respectively. On administration of increasing doses of garlic (250 mg to $500 \mathrm{mg}$ ) in wistar rats induced with Aluminum phosphide, it was observed that the Packed cell volume and hemoglobin count decreased progressively from $38.14 \pm 6.98$ to $36.00 \pm 5.01$ and $11.70 \pm 1.38$ to $11.13 \pm 1.03$ respectively. However, administration of increased doses of garlic extracts in Aluminum phosphide induced toxicity led to an increase in red cell indices parameters such as $\mathrm{MCH}$, MCHC and MXD while platelet count shows a significant $\mathrm{P}<0.05$ increase from $176.50 \pm 9.88$ to $249.86 \pm 42.67$. In rats where garlic alone was administered (without aluminum phosphide induced toxicity), the PCV dropped significantly $(\mathrm{P} \leq 0.05)$ from $43.33 \pm 4.45$ to $33.83 \pm 3.87$. platelet count, $\mathrm{MCV}$ and $\mathrm{MCH}$ increased on garlic only administration while hemoglobin, MCHC and MXD showed non-significant decrease. Aluminium phosphide induced toxicity brought about a non-significant increase in total white blood cell count and neutrophils count as indicated by the rise from $7.50 \pm 4.42$ to $9.00 \pm 7.11$ and $40.33 \pm 20.35$ to $48.57 \pm 18.62$ respectively thus agreeing with the work by Anand et al. [26] that Aluminium phosphide toxicity leads to an increased production of white blood cells (inflammatory response). However, administration of garlic extract aggravated the effect as it significantly increased $\mathrm{P}<0.05$ the total WBC count to $15.75 \pm 1.11$ on administration of $250 \mathrm{mg}$ dose although it dropped to $10.23 \pm 3.64$ after an increased dose of $500 \mathrm{mg}$. Neutrophils also showed a significant increase $\mathrm{P}<0.05$ on administration of $500 \mathrm{mg}$ dose of garlic. Of all the white blood cell parameters, only lymphocyte count decreased significantly $(\mathrm{P}<0.05)$ from $37.43 \pm 18.40$ to $22.57 \pm 9.80$ after administration of increased dose of garlic extract in Aluminum phosphide induced toxicity. Thus, the findings of this study indicates that while Aluminum phosphide causes a decrease in packed cell volume, it also brings about a general increase in other hematological parameters such as red cell indices and white blood cell parameters. However, the combined administration of aluminum phosphide and garlic extract aggravated increase in WBC alongside with total number of platelets. As part of the WBC being increased, the neutrophils are higher in number showing that there is an inflammatory response to injury in the body also an increased response of platelets is also indicative of inflammatory mobilization to the site of injury in the body. This response is seen more in group $\mathrm{C}$ and group D. The plates labeled 1-5 show the photograph of the livers of the animals used for the study. Plate 1 shows the normal morphology of the liver with central vein (CV) and sinusoidal space (S) and hepatocytes consistent with normal histology of the liver. A liver sinusoid is a capillary lined with endothelium and Kupffer cells found in healthy liver [25].

Plate 2 show both congestion (C) and necrosis (N) as well as Kupffer cells (K) Kupffer cells are macrophages local to the liver which perform primary immune surveillance [28]. A study carried out by Sogut et al. [7] on the effects of Aluminum Phosphide in the liver revealed that the histopathological examination of the liver displayed sinusoidal congestion. The present study, the Aluminum Phosphide was found to be hepatotoxic at the concentration administered.

Plate 3 shows the normal morphology of the liver after administration of Aluminum Phosphide and garlic at the concentration of $250 \mathrm{mg} / \mathrm{l}$. The slides show congestion, necrosis, and fatty infiltration $(\mathrm{F})$ on microscopic study, the liver showed central venous congestion, degeneration, hemorrhage, sinusoidal dilation, bile stasis, centrilobular necrosis, Kupffer cell hyperplasia, infiltration, by mononuclear and fatty change [27]. Aluminum Phosphide when combined with garlic at that concentration was shown to have a more harmful effect on the liver. Plate 4 shows the morphology of the liver after the administration of Aluminum Phosphide and garlic at the concentration of $250 \mathrm{mg} / \mathrm{l}$. The slides labeled D showed hepatocytes, congestion (C), necrosis $(\mathrm{N})$ and the presence of Kupffer cells $(\mathrm{K})$, their 
presence indicates inflammation, the obstruction of sinusoids which impedes blood flow is known as congestion, it also shows changes like central venous congestion and mononuclear infiltration of hepatocytes in accordance with Brunt et al. [26]. According to Jian et al. [28], liver injury seen as various hepatic changes as observed in the plates is a result of collective damage to hepatocytes through means such as lipid peroxidation and oxidative stress. Slides from groups B, C and D prove that toxic effects of certain substances can be exaggerated by other substances [6] as seen in the level of injury associated with microscopic structure.

Plate 5 shows group $\mathrm{E}$ which displays a slide of liver tissue from animal administered with oil only, exhibiting hepatocytes, intact sinusoidal spaces, and central vein all consistent with normal liver histology. It also contains group $F$ which shows central vein and sinusoidal space of liver of animal administered with garlic $(250 \mathrm{mg} / \mathrm{l})$.

The plates labeled 6-8 represent the photo micrograph of the kidney of the animals used in the above study. The plate labelled 6 shows the morphology of the kidney after the administration of the various treatment for 7 days, slide A, E and $\mathrm{F}$ which represent animals in the above group shows kidney histology including normal glomeruli and distal tubules.

Plate 7 shows area of tubular necrosis, contracted glomeruli with marked presence of mesangial cells for group B. Plate 8 shows membranous defect, contracted glomeruli with marked presence of mesangial cells for group $\mathrm{C}$ and group D shows areas of tubular necrosis with mesangial cells proliferation. In a study carried out by Chugh et al., kidney was found among the organs that were congested [29]. Findings shows that the kidney was congested in all cases, necrosis and area of degeneration and regeneration was see in $78 \%$ of the cases. Shah et al. [30] in his findings shows that tubular degeneration is present in the kidney. Sands and Verlender [31] reported that mesangial cells based on their resemblance with smooth muscle cells proliferate during glomerular injury thus leading to proliferative glomerular lesions. Severe exposure of Aluminum phosphide may also result in proteinuria or glucosuria (low molecular weight proteins or glucose in the urine) indicating kidney damage. Pathological examination of exposed laboratory animal tissue and results of post-mortem examinations of phosphine poisoning victims generally indicate hypoxia, with evidence of local trauma in the kidney [32].

Another change is relocation of $\mathrm{Na}+\mathrm{K}+-\mathrm{ATPase}$ pumps and integrins to the apical membrane. Cell death occurs by both necrosis and apoptosis. Sloughing of live and dead cells occurs, leading to cast formation and obstruction of the tubular lumen. Activation of the renal immune system with damage to tubular cells stimulating local secretion of proinflammatory cytokines in turn induces further necrosis [33]. Clinical signs of phosphine poisoning in animals can occur within minutes to hours of ingestion of a toxic dose, which can lead to coma and death. Clinical signs of kidney injury can occur 48-72 hours after exposure to the toxin [34].

\section{CONCLUSION}

The present study concluded that the oral ingestion of Aluminium Phosphide induces hepatotoxicity and inflammation of the liver and kidney. It also shows that the use of garlic at various concentrations $(250 \mathrm{mg} / \mathrm{l}$ and $500 \mathrm{mg} / \mathrm{l}$ ) aggravates the tissue damage even more, and also garlic extract does not have ameliorative effect on aluminum phosphide toxicity on the liver and kidney of albino wistar rats.

\section{ETHICAL APPROVAL}

Animal ethics committee approval has been taken and preserved by the author for this study.

\section{COMPETING INTERESTS}

Authors have declared that no competing interests exist.

\section{REFERENCES}

[1] Soar J., Perkins G. D., Abbas G., Alfonzo A., Barelli A., Bierens J. J., Brugger H. Deakin C. D., Dunning I. J., Georgiou M., Handley A. J. Lockey D. J., Paal P., Sandroni C., Thies K. C., Zideman D. A., Nolan J. P. (2010). "European Resuscitation Council Guidelines for Resuscitation 2010 Section 8. Cardiac arrest in special circumstances: Electrolyte abnormalities, poisoning, drowning, accidental hypothermia, hyperthermia, asthma, anaphylaxis, cardiac surgery, trauma, pregnancy, electrocution". Resuscitation. 81 (10): 1400-1433.

[2] Mehrpour, O., and Singh, S. (2010) Rice tablet poisoning: a major concern in Iranian population. Hum Exp Toxicol. 29:701-702.

[3] Sudakin D. L. (2005). Occupational exposure to aluminum phosphide and phosphine gas? A suspected case report and review of the literature. Human Experimenal Toxicology. 24:27-33

[4] Singh, D., Dewan, I., Pandey, A., and Tyagi, S. (2003). Spectrum of unnatural fatalities in the Chandigarh zone of north-west India - a 25 year autopsy study from a tertiary care hospital. Journal of Clinical Forensic Medicine, 10:145-152.

[5] Ranga, G., Dwivedi, S., Agarwal, M., and Kumar, D. (2004) Aluminium phosphide poisoning in a young adult: a suicidal cardiotoxin simulating myocardial ischemia. Journal of Indian Academic Clinical Medicine, 5:369.

[6] Gupta, B., Hapani, J., and Shah, V. (2006). Current trend of poisoning in Jamnagar. Journal Indian Academic and Forensic Medicine.28:9092.

[7] Singh, S., Singh, O., Wig, N., Jit, I., and Sharma, B. (1996). Aluminium phosphide ingestion-Aclinico-pathological study. Journal of Toxicololgy and Clinical Toxicology. 34: 703-706.

[8] Bagheri F., Gol A., Dabiri S., Javadi A. (2011). Iran the American Journal of Kidney Diseases. 5(3):194-200.

[9] Adejumo, I. O., Ologhobo, A. D., Alabi O. O., Bamiro, O. M. (2014) Potential Hazards due to Misuse of Aluminium Phosphide in Kaduna. Nova Journal of Engineering and Applied Sciences Vol. 3(1): 1-7.

[10] Ictali, B., Miguil, M., Moutawakkil, S., Bouaggad, A., Guartit, A. Abbassi, O., and Aguide, M. (1995). Acute phostoxin poisoning. Press Medicine. 24: 611-612.

[11] Nagar, K. (1985). Aluminium phosphide poisoning. Journal of Associate Physicians of India, 33:819-820.

[12] Proudfoot, A. (2009). Aluminium and zinc phosphide poisoning. Clinical Toxicology (Philadelphia). 47: 89-100.

[13] Singh, Seema \& Srivastava, Sanjeev \& Bhardwaj, Ashwani \& Owen, Laurie \& Singh, Ajay. (2010). Singh S, Srivastava SK, Bhardwaj A, Owen LB, Singh APCXCL12-CXCR4 signaling axis confers gemcitabine resistance to pancreatic cancer cells: a novel target for therapy. Br J Cancer 103(11): 1671-1679. British journal of cancer. 103. 1671-9. 10.1038/sj.bjc.6605968.

[14] Miranda-Contreras, L., Gómez-Pérez, R., Rojas, G., Cruz, I., Berrueta, L., Salmen, S., Colmenares, M., Barreto, S., Balza, A., Zavala, L., Morales, Y., Molina, Y., Valeri, L., Contreras, C.A. and Osuna, J.A. (2013), Occupational Exposure to Organophosphate and Carbamate Pesticides Affects Sperm Chromatin Integrity and Reproductive Hormone Levels among Venezuelan Farm Workers. Journal of 
Occupational Health, 55: 195-203. https://doi.org/10.1539/joh.120144-FS.

[15] Uzun FG, Kalender Y. Chlorpyrifos induced hepatotoxic and hematologic changes in rats: the role of quercetin and catechin. Food Chem Toxicol. 2013 May; 55:549-56. doi: 10.1016/j.fct.2013.01.056. Epub 2013 Feb 8. PMID: 23402859.

[16] Anger, F., F. Paysant, F. Brousse, I. Le Normand, P. Develay, Y. Gaillard, A. Baert, M.A. Le Gueut, G. Pepin, and J.P. Anger. 2000 Fatal aluminum phosphide poisoning. J. Anal. Toxicol. 24(2):90-92. [PubMed].

[17] Mostafalou, S., Karami-Mohajeri, S., \& Abdollahi, M. (2013) Environmental and population studies concerning exposure to pesticides in iran: a comprehensive review. Iranian Red Crescent medical journal, 15(12), e13896. https://doi.org/10.5812/ircmj.13896.

[18] Kariman et al.,2012 Hamid Kariman \& Kamran Heydari \& Mohammad Fakhri \& Ali Shahrami \& Ali Arhami Dolatabadi \& Hossein Ali Mohammadi \& Morteza Gharibi (2012) Aluminium Ph J. Med. Toxicol. 8:281-284 DOI 10.1007/s13181-012-0219-1osphide Poisoning and Oxidative Stress Serum Biomarker Assessment.

[19] Arun, 2002 Synthesis and Oxidation Reactions of a User- and EcoFriendly Hypervalent Iodine Reagent January 2002Tetrahedron Letters 43(4):569-572 DOI: 10.1016/S0040-4039(01)02217-1.

[20] S.O. Ajeigbe, A.K. Mohammed, I.A. Yahaya and A.O. Oyelowo, 2012. Effect of Processing Techniques on Levels of Minerals and Antinutritional Factors of Canavalia ensiformis. Pakistan Journal of Nutrition, 11: 1121-11.

[21] Knight MW. Zinc Phosphide Intoxication. In: Cote E, Ed. Clinical Veterinary Advisor: Dogs and Cats. St. Louis: Mosby Elsevier, 2007, 1170-1171.

[22] Afolabi OK, Aderibigbe FA, Folarin DT, Arinola A, Wusu AD. Oxidative stress and inflammation following sub-lethal oral exposure of cypermethrin in rats: mitigating potential of epicatechin. Heliyon. 2019 Aug 9;5(8): e02274. doi: 10.1016/j.heliyon.2019.e02274. PMID: 31440603; PMCID: PMC6700339.

[23] Epson et al,2006 Effect of acute aluminum phosphide exposure on ratsA biochemical and histological correlation October 2012 Toxicology Letters 215(1):62-69 DOI: 10.1016/j.toxlet.2012.09.020 Source PubMed.

Anand et al.,2011 Effect of acute aluminum phosphide exposure on rats-A biochemical and histological correlation October 2012 Toxicology Letters 215(1):62-69 DOI: 10.1016/j.toxlet.2012.09.020.

[24] Jain, A., Nigam, M., Garg, S., Dubey, B., and Arora, A. (2005) Aluminium phosphide poisoning - Autopsy findings. JIAFM, 27(1):35-39.

[25] Brunt, E., Wong, V., Nobil, V., Day, C., Sookoian, S., and Maher, J. (2014). Pathology of the liver sinusoids. Histopathology,64:20-907.

[26] Ashok Kumar Jain., Manish Nigam., Garg S., Dubey B. P., Arora A (2005). Aluminium Phosphide Poisoning Autopsy Findings. Journal Indian Academy Forensic Medicine, 2005: 27 (1). ISSN 0971-0973.

[27] Gupta, V., and Gill, K. (2000). Influence of ethanol on lead distribution and biochemical changes in rats exposed to lead. Alcohol,20:9-17.

[28] Chugh, S., Arora, V., Sharma, A., and Chugh, K. (1996). Free radical scavengers \& lipidperoxidation in acute aluminium phosphide poisoning. Indian Journal Medicine Research. 104: 190-193.

[29] Arora, B., Punia, R., Kalra, R., and Chugh, S. (1995). Histopathological changes in aluminium phosphide poisoning. Journal of Indian Medical Association, 93, 380-381.

[30] Shadnia S., Sasanian G., Allami P., Hosseini A., Ranjbar A., AminiShirazi N. (2009). A retrospective 7-years study of aluminum phosphide poisoning in Tehran: opportunities for prevention Human Experimental Toxicology, 28 (4) 209-213.

[31] Sands J. M., Verlander J. W. (2010). In Comprehensive Toxicology, Renal Toxicology. Retrieve 11/10/1019.

[32] Gehring P. J., Nolan R. J., Watanabe P. G., Schumann A. M. (1991). Chapter 14: Solvent, Fumigants and Related Compounds, In Hayes, W.J. and Laws, E.R., Jr. (Eds.) Handbook of Pesticide Toxicology, Academic Press, New York, NY.

[33] Fedor Kundert., louise Planten., Hans-Joachim Anders. (2018). Immune mechanisms in the different phases of acute tubular necrosis. Kidney Research and Clinical Pratice, retrieve 10/9/2019.

[34] Mathai Ashu., Bhanu Madhuritasingh. (2010). "Acute aluminium phosphide poisoning: Can we predict mortality?". Indian Journal of Anaesthesia. 54 (4): 302-307. 